\title{
Dimensión material de un medio de memoria digital. El caso de Archivos de la Represión
}

The Material Dimension of a Digital Memory Medium. The case of Archivos de la Represión

\author{
Guillermo Salvador Ortega Vázquez* \\ gmoortegava@gmail.com \\ ORCID: https://orcid.org/0000-0002-1814-6871 \\ Maestro en Comunicación \\ Universidad de Guadalajara \\ México
}

\section{Resumen}

El surgimiento de archivos digitales relacionados con periodos de represión y violación de derechos humanos ha ampliado las prácticas de investigación sobre el pasado reciente. En 2018, la organización Artículo 19, la Comisión de la Verdad de Guerrero y El Colegio de México dieron a conocer el sitio web Archivos de la Represión, plataforma de resguardo y acceso a una parte del acervo documental legado, principalmente, por la Dirección Federal de Seguridad y la Dirección General de Investigaciones Políticas y Sociales durante la denominada Guerra Sucia en México. Este trabajo em-

* Egresado de la Maestría en Comunicación de la Universidad de Guadalajara. Su línea de investigación se concentra en los estudios de memoria y los archivos digitales. Actualmente se desempeña como secretario técnico de Ixaya. Revista Universitaria de Desarrollo Social y como archivista en el Archivo Histórico de la Universidad de Guadalajara. Dos de sus publicaciones más recientes son los artículos "Mediatización y digitalización del patrimonio cultural. El caso de la Mediateca del Instituto Nacional de Antropología e Historia" (2019) y "La memoria como problema comunicativo. Genealogía y construcción conceptual de los medios de memoria: el caso de archivos de la represión y memoria abierta” (2019). 
plea la propuesta teórica de las culturas del recuerdo de Astrid Erll (2011), en especial la dimensión material, para analizar y observar al archivo digital como un medio de memoria que trastoca las narrativas sobre el pasado represivo a través de la implementación de tecnologías mediales.

\section{Palabras clave}

Archivos de la Represión, archivos digitales, medio de memoria, Guerra Sucia, culturas del recuerdo.

\section{Abstract}

The emergence of digital archives related to periods of repression and human rights violations has widened investigative practices on the recent past. In 2018, organization Artículo 19, Comisión de la Verdad de Guerrero and El Colegio de México released Archivos de la Represión, a digital platform to preserve a portion of the archives of the Dirección Federal de Seguridad and the Dirección General de Investigaciones Politicas y Sociales during the Mexican Dirty War. By using the concept of "cultures of memory" as proposed by Astrid Erll (2011), especially its material dimension, we seek to analyse and observe the digital archive as memory medium that contradicts narratives of repression.

\section{Keywords}

Archives of Repression, digital archives, memory medium, Guerra Sucia, cultures of memory.

\section{Introducción}

Archivos de la Represión, ${ }^{1}$ proyecto generado por Artículo 19, la Comisión de la Verdad de Guerrero (Comverdad) y El Colegio de México (Colmex), surgió en 2018 como un archivo digital que construye una contranarrativa sobre el pasado represivo en México. Este archivo contiene 310000 fotografías obtenidas por la Comverdad durante la investigación documental que realizó entre 2012 y 2014 en el Archivo General de la Nación (AGN). El contenido y valor histórico de estos documentos radica en su carácter testimonial del periodo conocido popularmente en México como Guerra Sucia

1 https://archivosdelarepresion.org/ 
(1960-1980), escenario donde el Estado mexicano, a través de instituciones como la Dirección Federal de Seguridad (DFS) y la Dirección General de Investigaciones Políticas y Sociales (DGIPS), cometió una serie de acciones catalogadas como violaciones a los derechos humanos; entre ellas destacan crímenes como la desaparición forzada y la tortura.

Los archivos de la represión, más allá del caso de estudio que presenta esta investigación, son un fenómeno documental y medial relacionado estrechamente con la defensa de los derechos humanos. Para el Consejo Internacional de Archivos (ICA, por sus siglas en inglés) y la Organización de las Naciones Unidas para la Educación, la Ciencia y la Cultura (UNESCO), los archivos de la represión, también enunciados como archivos de derechos humanos, son todos aquellos grupos documentales producidos por dependencias y organismos represivos desde la configuración del Estado moderno (González Quintana, 2005). La relación concomitante entre archivos, represión y derechos humanos acentúa y acompaña el surgimiento del archivo digital en cuestión.

Además de describir sus características históricas e informativas, este trabajo analiza y conceptualiza dicho archivo bajo la mirada de los estudios de memoria, de manera específica a partir de la propuesta tridimensional que construye Astrid Erll (2011) desde el sistema conceptual de las culturas del recuerdo. Según Erll, las dimensiones social, mental y material constituyen el proceso de construcción colectiva de la memoria. En esta investigación, se aborda la dimensión material, la cual está identificada por el estudio y el análisis de los medios de memoria y explica la relación del estudio cultural y semiótico de la memoria con los medios de comunicación. Como ocurre con la memoria, bajo el concepto de medio se han diseñado múltiples definiciones; sin embargo, la propuesta de Erll resalta la capacidad de mediación del proceso semiótico, que define al medio de memoria colectiva.

Este artículo emplea como propuesta metodológica el análisis narrativo de los medios de memoria, que tiene como objetivo visibilizar las narraciones ${ }^{2}-$ a través de sus funciones y estructuras- sobre el pasado y

2 Estas narraciones fueron observadas a través de la arquitectura y diseño web del archivo digital, documentos oficiales producidos por las instituciones participantes, notas de prensa y entrevistas semiestructuradas a integrantes de Artículo 19, la Comverdad, investigadores y usuarios.

Ortega, G. S. (2021). Dimensión material de un medio de memoria digital. El caso de Archivos de la Represión. Iberoforum. Revista de Ciencias Sociales, Nueva Época, 1(1), 1-37, artículo e000141. https://doi.org/10.48102/if.2021.v1.n1.141 Licencia Pública Internacional - CC BY NC SA 4.0 
los procesos de construcción de memoria que instituciones y sujetos inscriben en el medio de memoria. Las preguntas principales que se desprenden de esta propuesta conceptual en el contexto de este artículo son: ¿cómo se llevan a cabo los procesos de producción y circulación del recuerdo en el medio de memoria colectiva Archivos de la Represión? y ¿cuáles son los significados que, para la práctica colectiva del recuerdo, se construyen en el entorno digital del medio de memoria?

Este texto centra su análisis en las características materiales y sociales que integran el acervo digital Archivos de la Represión, observado como medio de la memoria colectiva. En el ámbito social del medio de memoria, se revisa el proceso de institucionalización para convertir los documentos digitalizados por la Comverdad en el proyecto Archivos de la Represión. Más allá de la transformación de las características tecnológicas, nuestro interés apunta hacia las acciones que las instituciones implementaron para fijar el archivo dentro de la memoria colectiva sobre el periodo de contrainsurgencia en México. Otra de las categorías que se aborda es la observación del marco medial en el que surge el proyecto. Se hace especial hincapié en aquellos medios que también han construido narrativas alrededor de las políticas de represión en México. Todavía en el ámbito social del medio de memoria, se abordan las funciones que desempeña Archivos de la Represión, específicamente su papel como medio de almacenamiento y circulación del recuerdo.

La segunda parte del análisis del medio de memoria está dedicada exclusivamente a la revisión de sus características materiales. Aquí se describen con profundidad los instrumentos comunicacionales que integran el archivo, desde el texto escrito hasta la imagen y el video. También se analiza lo relacionado a las tecnologías mediales que constituyen el proyecto, en especial el entorno digital y las diferentes herramientas que se utilizan. La observación de la dimensión material del medio de memoria no atiende a las características tangibles de un archivo digital, sino a la posibilidad de describir sus herramientas digitales como parte de una estructura semiótica que construye una narración sobre el pasado.

A propósito del concepto "medio de memoria", Erll (2011) señala que éste "sólo se constituye a través del actuar conjunto de factores que se establecen en diversos niveles" (p. 186). Así, cada una de las categorías enunciadas anteriormente corresponde a los niveles que integran un fenómeno medial y, en lo consecuente, lo definen como un medio de memoria. Este 
último concepto es el elemento que supone la elección de la teoría de las culturas del recuerdo de Erll (2011) para esta investigación. En su capacidad de mediación, se encuentra la posibilidad de aproximarse a la naturaleza mnemónica y comunicacional del pasado que reside en el archivo y en los procesos de organización e interpretación que lo atraviesan.

\section{Dimensión social del medio de memoria}

La insistencia en describir las características sociales de un medio de memoria, incluso como una categoría del mismo concepto, se desprende de la posición que adopta Erll (2011) al considerar que un medio de memoria lo es en tanto su proceso de institucionalización social. Aunque el ámbito material del medio de memoria es importante para comprender sus funciones comunicacionales del recuerdo, es su carácter social el que le permite transitar de fenómeno medial a medio de memoria. La preponderancia que Erll atribuye al proceso de institucionalización es una de las herencias epistemológicas de la memoria cultural definida por Jan Assman (2011) y Aleida Assman (2012). Allí donde se construye la memoria cultural, existe un trasfondo marcado por la canonización de sujetos y procesos, es decir, la actuación de instituciones especializadas en el conocimiento histórico y las narraciones del pasado, y la producción de objetos, lugares y procesos que dan cuenta de esta especialización.

Para el caso de Archivos de la Represión, se describe el proceso de institucionalización a partir del análisis de Artículo 19, la Comverdad y el Colmex como instituciones especializadas en el conocimiento informativo, testimonial e histórico; característica que permite plantear la constitución de un canon archivístico.

\section{Surgimiento del proyecto Archivos de la Represión}

En uno de los boletines de prensa emitidos por Artículo 19, se narra la gestación del proyecto Archivos de la Represión. Este organismo "tuvo acceso a una gran parte de esos archivos mediante una donación de personas que fueron comisionadas de la ex Comisión de la Verdad del Estado de Guerrero. En conjunto con la Northwestern University y El Colegio de México, se ha trabajado desde hace meses para hacer públicos dichos archivos" (Artículo 19, 2018). Este fragmento ofrece claridad en cuanto a la formación del escenario multi-institucional del archivo digital. 
El trabajo de la Comverdad debe ser revisado y destacado no sólo por su actuar relacionado con el rescate y digitalización documental del material archivístico, sino por la lucha que emprendieron en el periodo de 2012 a 2014 para esclarecer los crímenes cometidos por el Estado en Guerrero durante la denominada Guerra Sucia. ${ }^{3}$ El trabajo de la Comverdad se incorporó al espacio dedicado al Archivo Íntegro. Con esta acción, se reconoce el trabajo de la Comisión y, lo más importante, se valora su papel como una institución especializada en la construcción de narrativas y testimonios sobre el pasado, específicamente sobre el periodo de contrainsurgencia en Guerrero. En otras palabras, la inclusión de la Comverdad como un organismo activo y visible dentro del archivo digital es un rasgo que posibilita el proceso de institucionalización del medio de memoria en su fase de producción.

Ante la imposibilidad de definirse como una institución especializada en todos los campos que atraviesan la producción de un archivo digital de contenidos históricos, Artículo 19 recurrió a la colaboración del Colmex y la Northwestern University para diseñar las características archivísticas, históricas y digitales del proyecto. La aportación del Colegio, especialmente del área de su biblioteca, fue la guía y experiencia en la elección del software para el manejo y catalogación de los documentos digitalizados (Jessica Alcázar. Comunicación personal, 20 de enero de 2020). En cuanto a la Northwestern University, su participación se formalizó con la transferencia de recursos económicos para el desarrollo del proyecto y con la asesoría del Center for Research Libraries (CRL) en materia de catalogación archivística en entornos digitales (María de Vecchi. Comunicación personal, 20 de enero de 2020). Ambas instituciones deben ser analizadas a través de su relación y colaboración en Archivos de la Represión, en tanto su carácter de instituciones especializadas en el conocimiento histórico y archivístico.

En lo que respecta al trabajo de Artículo 19, si bien sus actividades no están relacionadas directamente con el diseño y producción de archivos digitales históricos, podemos reconocer su ámbito de especialización en lo referente a la defensa y promoción de la libertad de expresión y acceso

3 Además del trabajo de digitalización de documentos, la Comisión elaboró el Informe Final donde suma el rescate de testimonios de víctimas de desaparición forzada durante el periodo de contrainsurgencia.

Ortega, G. S. (2021). Dimensión material de un medio de memoria digital. El caso de Archivos de la Represión. Iberoforum. Revista de Ciencias Sociales, Nueva Época, 1(1), 1-37, artículo e000141. https://doi.org/10.48102/if.2021.v1.n1.141 Licencia Pública Internacional - CC BY NC SA 4.0 
a la información (Artículo 19, 2020). Como apuntamos en la sección de la dimensión social, la narrativa preponderante en Archivos de la Represión concibe la publicación de estos documentos históricos como parte de un ejercicio de acceso a la información. Sobre esta narrativa, en el sitio web del archivo se expone que

los documentos que se ponen aquí a disposición pública no contienen toda la verdad histórica, pero forman parte importante de ella. No toda la información que estos documentos contienen narra verídicamente hechos, tomando en cuenta que hay información arrancada por tortura, o elaborada para distorsionar hechos. (Article 19)

Existe una acción reiterada de enunciar el carácter informativo de los documentos históricos por parte de Artículo 19. Aunque este valor informativo es inherente al archivo, los documentos poseen además valores testimoniales, históricos y de evidencia. Si bien éstos no son borrados, sí se concibe como trascendental su condición informativa. Este hecho permite configurar el trabajo de Artículo 19, en su relación con Archivos de la Represión, como una actividad especializada en el rubro de acceso a la información.

Las instituciones participantes no son los únicos actores en la constitución de Archivos de la Represión como medio de memoria. Para analizar las coordenadas y procesos que impulsaron la institucionalización del archivo digital, es vital conocer la participación y colaboración de otros especialistas y usuarios.

Entre los especialistas que colaboraron en alguna fase del proceso de producción del archivo digital se encuentran los historiadores Francisco Robles Gil Martínez del Río y Camilo Vicente Ovalle. Su papel como asesores del proyecto debe ser analizado en tanto portadores de memoria especializados en el conocimiento del pasado. La lectura y la interpretación de los archivos realizadas por Robles Gil y Vicente añaden nuevos niveles y significaciones al proceso de institucionalización del archivo digital. Durante la presentación del proyecto, Robles Gil sostuvo que Archivos de la Represión es

un portal no solamente digital sino también narrativo, esto es, nos da la posibilidad de dislocar las versiones hegemónicas tanto oficiales

Ortega, G. S. (2021). Dimensión material de un medio de memoria digital. El caso de Archivos de la Represión. Iberoforum. Revista de Ciencias Sociales, Nueva Época, 1(1), 1-37, artículo e000141. https://doi.org/10.48102/if.2021.v1.n1.141 Licencia Pública Internacional - CC BY NC SA 4.0 
como de oposición y así trazar otras grafías desde las cuales remover el sedimento de un pasado que insiste ser presente. Un territorio que de tan secreto fue por mucho tiempo opacado tanto por el saber policiaco, jurídico e histórico, es decir, era patrimonio de la nación. (Artículo 19, 2018)

Robles Gil devela los distintos saberes que confluyen en el análisis de los documentos de la represión; entre ellos, el histórico, aunado a la posibilidad de construir nuevas versiones y narraciones contrahegemónicas del pasado. Esta reconstrucción de versiones, materializada en el archivo digital, confronta el canon y la narrativa oficial de los documentos de archivo, configurando un nuevo modelo de aproximación, organización y búsqueda. En sintonía con estas interpretaciones y significaciones del archivo, en tanto fuente histórica, Vicente (2019) realiza una crítica hacia su naturaleza: "el archivo también produce un campo de archivo, es decir, un campo de acción de este archivo que no sólo se circunscribe a los mecanismos archivísticos, sino que es campo de archivo mucho más grande, en donde se van entretejiendo más voces a partir del archivo, ésa es otra de las potencias narrativas". El campo de especialización de las instituciones revisadas privilegiaba las características informativas, testimoniales y archivísticas del proyecto. La participación de Robles Gil y Vicente, desde su carácter de historiadores, estimula la revisión de los documentos a partir de una perspectiva historiográfica, es decir, una aproximación que analiza el contenido de los documentos y la forma en la que fueron escritos. El campo de archivo al que se refiere Vicente (2019) es una observación de segundo orden al dispositivo archivístico. A partir de este tipo de colaboraciones, Artículo 19 incorporó dentro del sitio web algunos textos que, a manera de presentación, brindan guías de lectura informativa e histórica sobre el archivo. Por ejemplo: "cabe recordar que los archivos obtenidos han sido construidos desde el poder, creándose narrativas específicas" (Article 19).

El proceso de institucionalización del medio de memoria no sólo se lleva a cabo en la fase de producción, en este caso, del archivo digital. La fase de recepción y consulta del medio es tan importante como aquélla dedicada a la producción. Para Erll (2011) es valioso reconocer la forma en que se utiliza un medio de memoria, que es "todo aquello que un colectivo conciba, de manera mediada, como pasado" (p. 186). 
Para revisar la fase de recepción, incluiremos parte de los comentarios que compartió Valentina López en su papel de usuaria de Archivos de la Represión. Además de identificarlo como un espacio de investigación del pasado - especialmente para las organizaciones urbanas de los 70 y el caso de la Liga 23 de Septiembre-, López explica las diferencias entre asistir al AGN y utilizar el archivo digital: "La principal diferencia es la accesibilidad, como te decía, yo fui al AGN un día, siempre quise ir para ver qué había allí; me llevó todo el día sacar la credencial y para cuando terminé de tramitarla ya iban a cerrar" (Valentina López. Comunicación personal, 21 de abril de 2020). Más allá de las herramientas digitales que ofrece Archivos de la Represión, se rescata la relación entre los dos archivos y se acentúa la posibilidad de acercarse al pasado mediante el acervo digital.

Además de la participación de instituciones y portadores de memoria especializados en el conocimiento sobre el pasado, otro de los elementos que corrobora el proceso de institucionalización del medio de memoria es la conformación de un canon, que dota de un carácter organizativo al medio, según lo explica Jan Assman (2011). Para evidenciar la institucionalización de un medio de memoria es preciso dar cuenta de las normas y principios bajo los que se formula; para el caso de nuestra investigación, el canon que se instituye es el del archivo. Para Eduardo Kingman (2012), "los archivos constituyen acopios de documentos relacionados con los procesos de organización del estado y las instituciones. Tanto los sistemas médicos, educativos, judiciales, como de seguridad producen archivos; esto es, un conjunto de comunicaciones, reportes, diarios de campo, estadísticas, que organizan sus prácticas" (p. 124).

En Archivos de la Represión, una de las diferencias sustanciales en la relación archivo y canon es el entorno digital. Esta mediación tecnológica puede ser una herramienta para fomentar el uso colectivo de los archivos y, en ese sentido, de la memoria social. El uso de la tecnología, desde este punto de vista, puede convertir los archivos en espacios sociales de la memoria que incluyan múltiples voces en busca de la verdad y la justicia (Ketelaar, 2008). El dinamismo que imprime la digitalización de los archivos produce la redefinición del concepto archivo; por ejemplo, Terry Cook (2013) explica que "el archivo hoy en día se considera de forma creciente como el lugar donde la memoria social ha sido (y es) construida. El documento, por lo tanto, se convierte en un significado cultural, una construcción mediatizada y cambiante, y no una plantilla vacía donde verter los actos y los he- 
chos" (p. 93). Esta reflexión aporta planteamientos relevantes; el principal de ellos es el que apunta a la construcción mediatizada de los acervos, allí donde se abren caminos al estudio comunicacional de los archivos como una representación del mundo. Respecto a los archivos de represión, Ludmila da Silva Catela (2012) sostiene que se han convertido en un territorio de disputa sobre el pasado, un escenario donde la idea de memoria colectiva se ha fragmentado en diferentes memorias e identidades, un artefacto documental que, simbólicamente, se ha percibido como mecanismo narrativo contra el olvido.

Los archivos dan cuenta de la organización de las instituciones; es en esta organización donde podemos objetivar los principios y normas que definen al medio de memoria. Para el caso de Archivos de la Represión, estos principios organizativos no son los generados por la DFS o la DGIPS, ${ }^{4}$ ni siquiera los desarrollados por la Comverdad dentro de su investigación. El archivo digital generó sus propias normativas y principios de catalogación, lo que dota de un canon único al medio y lo diferencia del establecido por el AGN. Es decir, las características y condiciones en las que se gestó el proyecto, aunadas a las herramientas tecnológicas que posee, permitió a Artículo 19 archivar, bajo sus propios cánones, los documentos históricos. La connotación de archivar posee un ejercicio de poder inherente que, por mucho tiempo, ha sido considerado, según lo explica Mario Rufer (2016), como "la herramienta que posibilita la historia, propia de los saberes hegemónicos" (p. 171). El archivo como depositario de la verdad histórica y la materialización del pasado está siendo resignificado con proyectos como éste, que extraen las prácticas de memoria sucedidas en los archivos públicos para llevarlas a los entornos digitales.

En la Tabla 1, se presenta una síntesis de las relaciones entre los portadores de memoria especializados, el área de conocimiento en la que se lleva a cabo la institucionalización y el canon establecido. Las categorías propuestas en el área de especialidad se desprenden de las funciones y estructuras narrativas que las instituciones o sujetos elaboraron; fueron obtenidas a partir de los documentos oficiales producidos por los mismos, el sitio web y las entrevistas.

4 Estas instituciones de seguridad e inteligencia son las principales productoras de documentación, junto con la Secretaría de la Defensa Nacional (SEDENA), que integra el acervo de los archivos de la represión.

Ortega, G. S. (2021). Dimensión material de un medio de memoria digital. El caso de Archivos de la Represión. Iberoforum. Revista de Ciencias Sociales, Nueva Época, 1(1), 1-37, artículo e000141. https://doi.org/10.48102/if.2021.v1.n1.141 Licencia Pública Internacional - CC BY NC SA 4.0 
Tabla 1. Institucionalización del medio de memoria por especialidad y canon

\begin{tabular}{|l|l|l|}
\hline \multicolumn{1}{|c|}{ Institución / Sujeto } & \multicolumn{1}{c|}{ Área de especialidad } & \multicolumn{1}{c|}{ Tipo de canon } \\
\hline $\begin{array}{l}\text { Comisión de la Verdad de } \\
\text { Guerrero }\end{array}$ & Testimonial & Archivo como verdad \\
\hline $\begin{array}{l}\text { El Colegio de México / } \\
\text { Northwestern University }\end{array}$ & Archivística / histórica & $\begin{array}{l}\text { Archivo como sistema de } \\
\text { información histórica }\end{array}$ \\
\hline Artículo 19 & Informativa & $\begin{array}{l}\text { Archivo como acceso a la } \\
\text { información }\end{array}$ \\
\hline Historiadores & $\begin{array}{l}\text { Histórica / } \\
\text { historiográfica }\end{array}$ & $\begin{array}{l}\text { Archivo como fuente his- } \\
\text { tórica y como dispositivo }\end{array}$ \\
\hline Usuarios & Informativo & $\begin{array}{l}\text { Archivo como acceso a la } \\
\text { información }\end{array}$ \\
\hline
\end{tabular}

Fuente: Elaboración propia

La tabla también muestra cómo se articulan los diferentes procesos que constituyen la institucionalización del medio de memoria a partir de la especialidad de los portadores de memoria que participan en su producción y recepción. La diversidad de especialidades y usos del canon se relaciona con el conjunto de niveles que integran un medio de memoria y con la heterogeneidad de comunidades del recuerdo que confluyen en Archivos de la Represión. Esta disparidad de posiciones posibilita definir al archivo digital como un sistema de comunicación abierto a la construcción de diferentes significaciones.

\section{Funciones del medio de memoria colectiva}

A partir de la descripción de Erll (2011) sobre las características sociales, institucionales y comunicacionales de los medios de memoria, se desprende un cuestionamiento esencial: "¿Para qué se utilizan entonces los medios en los procesos colectivos del recuerdo?" (p. 188). Tras esta pregunta se vislumbra la función que cumplen los medios en el marco de las normas y prácticas narrativas de las instituciones que los constituyen. Erll clasifica las funciones de los medios de memoria en tres grandes procesos: almacenamiento, circulación y evocación. Tratar de definir los procesos del recuerdo que se construyen en un medio de memoria desde una sola de sus funciones resulta problemático. Para Erll (2011), "sólo en muy pocas ocasiones se le puede atribuir claramente una determinada función a un determinado 
medio de la memoria. Los medios que han tenido más éxito en una cultura del recuerdo muestran de manera simultánea elementos de las tres funciones" (p. 188).

Al igual que Erll, comprendemos la dificultad de etiquetar bajo una sola función un medio de memoria. Incluso, en términos epistemológicos, consideramos que la constitución de un medio de memoria, en términos de su funcionalidad, debe presentar, irremediablemente, los procesos, prácticas y formas que den cuenta de su tránsito por las tres funciones. Es decir, un fenómeno medial puede ser conceptualizado en un medio de memoria en la medida en que estén presentes las características funcionales de almacenamiento, circulación y evocación. Estas características o fases funcionales se conciben más allá del propio archivo, por lo que la interacción de los usuarios es necesaria para que estos configuren, a la par de las instituciones diseñadoras, la definición de la naturaleza funcional del medio de memoria, en este caso, del archivo digital. Cada una de estas fases materializa los procesos sígnicos del recuerdo y el olvido, que permiten definir al medio de memoria como un sistema de información y comunicación.

Para argumentar esta posición teórica, se revisan a continuación las características y procesos de almacenamiento, circulación y evocación que permiten conceptualizar a Archivos de la Represión como un medio de memoria. La función de almacenamiento "se refiere a la tarea que cumplen los medios de almacenar contenidos (o bien, objetos) de la memoria colectiva y permitir que se pueda disponer de ellos a través del tiempo" (Erll, 2011, p. 189). El proceso esencial que define la función de almacenamiento, también llamada depósito, es el de materializar textualmente los recuerdos, es decir, asir a un soporte material las narrativas que sobre el pasado se construyen. Con soporte nos referimos a los sistemas de escritura, representaciones visuales, plataformas digitales, monumentos, entre otros. En esta objetivación textual del recuerdo, los medios de memoria almacenan y construyen un mensaje sobre el pasado, pero también sobre el medio mismo. La construcción de mensajes es uno de los principios comunicacionales que constituyen el medio de memoria.

¿Cómo podemos observar la función de almacenamiento en el caso de Archivos de la Represión? En este cuestionamiento radica el origen del propio proyecto digital. Ante la oportunidad de difundir las investigaciones documentales de la Comverdad, Artículo 19 accedió al disco duro que contenía 310000 fotografías de documentos. El siguiente paso fue la cons- 
trucción de un archivo digital. Esta acción revela el objetivo de otorgar un soporte digital que permitiera la perdurabilidad de los documentos digitalizados, es decir, al transformar las fotografías de los documentos en un archivo digital, se cumplió con la función de almacenamiento. Así como los sistemas de escritura o la fotografía funcionan como soporte y almacén del recuerdo, en los entornos digitales la acción de construir un archivo a partir de una estructura normativa y organizacional se convierte en una función de almacenamiento.

Artículo 19 no sólo generó acciones para atender la construcción de un archivo digital, sino que resguardó el trabajo que realizó la Comverdad durante su investigación documental. Para ello, diseñó una sección especial denominada "Archivo Íntegro no catalogado de la Ex Comverdad", que presenta las más de 300000 fotografías de los documentos, organizadas de acuerdo a los lineamientos y metodología que mantuvo la Comverdad. Esta acción también forma parte de los procesos de almacenamiento de Archivos de la Represión.

\section{Imagen 1. Archivo Íntegro no catalogado}

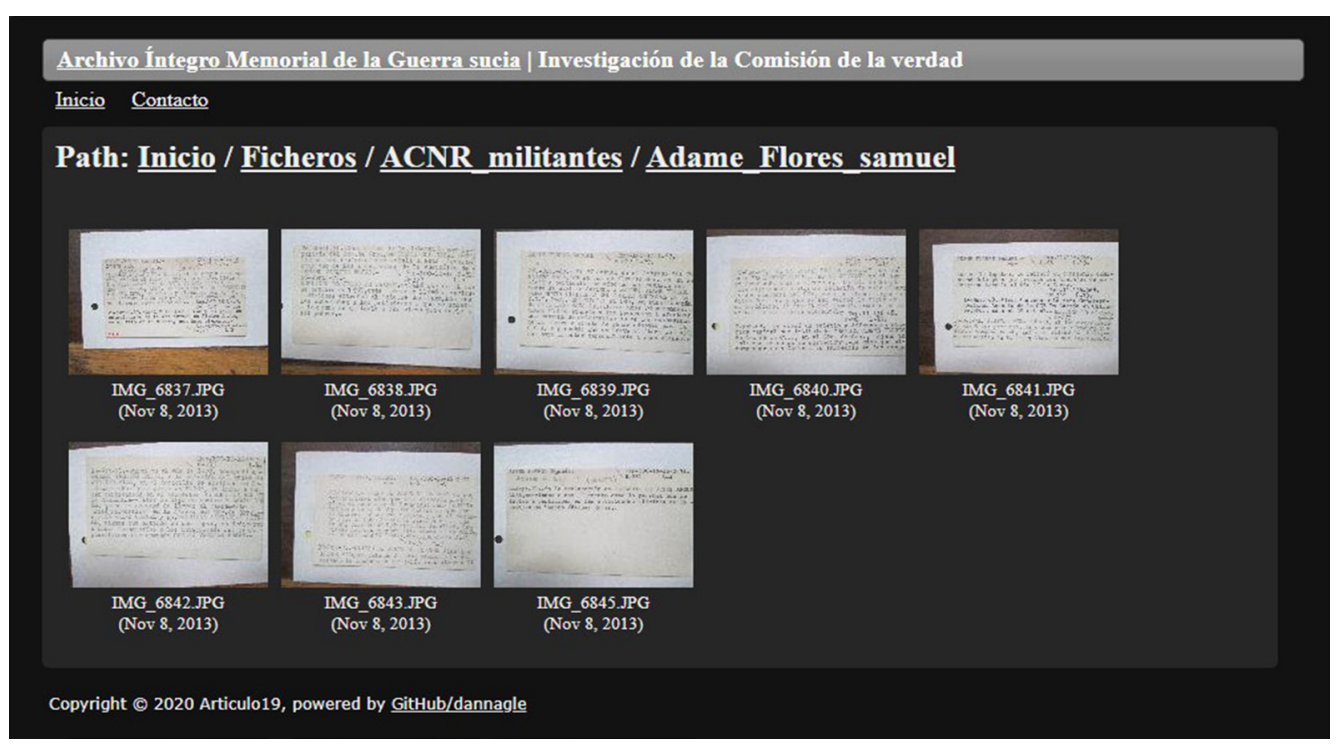

Fuente: Article 19. Archivos de la Represión

En lo que respecta a la función de circulación, Erll (2011) explica que "los medios de circulación cumplen la labor de sincronizar grandes comunidades del recuerdo en las cuales ya no es posible la comunicación 
face-to-face entre sus integrantes. La imprenta cumplió una función de este tipo en la modernidad temprana, las revistas la cumplieron en los siglos XVIII y XIX, la televisión y el internet la cumplen en la época de la globalización" (p. 189).

La tarea de diseño y desarrollo de un archivo digital, realizada por Artículo 19, es parte de la función de almacenamiento. La acción de llevar el archivo digital a un sitio web es el primer indicio para comprender los procesos de circulación del recuerdo; este hecho debe ser observado más allá de sus características digitales. El contexto de creación del archivo digital marca la pauta para reconocer la publicación de este archivo como una narrativa de acceso a la información que se opone a las restricciones del AGN.

Los archivos de estas dependencias se encuentran en el Archivo General de la Nación. Siendo documentos históricos se ha negado su publicidad, impidiendo el acceso efectivo al derecho a la verdad y contribuyendo a la impunidad que continúa desangrando a nuestro país. Usted tiene derecho de acceder, rectificar y cancelar sus datos personales, limitar su uso o divulgación, así como a oponerse al tratamiento de los mismos o revocarlos. (Article 19)

Los archivos sobre represión generados por el Estado mexicano poseen una trayectoria acentuada por el ocultamiento y la restricción. ${ }^{5}$ Incluso, la producción de los documentos por parte de las instituciones de seguridad configuraron al archivo como un artefacto de represión y de olvido. Del lado apuesto, la narrativa de acceso, presente en este archivo digital, debe ser intrepretada como parte de la función de circulación del recuerdo del medio de memoria. A casi dos años de la publicación de Archivos de la Represión, Jessica Alcázar describe que "el acervo digital tiene una

5 Ejemplos contemporáneos de estas acciones de restricción se plasman en la aprobación de la Ley Federal de Archivos de 2012. En esta legislación, se generaba un trato restrictivo y ambiguo de los documentos históricos. En el título cuarto, relacionado con el acceso a los archivos, de manera específica en su artículo 28, se mencionaba que: "Los documentos históricos confidenciales transferidos al Archivo General de la Nación o a los archivos históricos en calidad de custodia no formarán parte del archivo histórico de acceso público, hasta que concluya el plazo establecido en el artículo 27 de la presente Ley" (Ley Federal de Archivos, 2012). Bajo este argumento fue restringido el acceso a los documentos que integraban los denominados archivos de la represión.

Ortega, G. S. (2021). Dimensión material de un medio de memoria digital. El caso de Archivos de la Represión. Iberoforum. Revista de Ciencias Sociales, Nueva Época, 1(1), 1-37, artículo e000141. https://doi.org/10.48102/if.2021.v1.n1.141 Licencia Pública Internacional - CC BY NC SA 4.0 
gran aceptación. La última cifra que tenemos fueron casi 410000 visitas que pueden ser a los dos sitios (archivos). Tenemos una visita constante al archivo" (Comunicación personal, 20 de enero de 2020).

Las acciones de circulación del medio de memoria no se limitan al espectro digital: "se hacen presentaciones con familiares de víctimas, se tiene agenda en Guerrero. En eventos académicos presentamos el archivo como instrumento de memoria. Además, se acercan varias Comisiones de Verdad y búsqueda para cuestionarnos sobre el proyecto" (Jessica Alcázar. Comunicación personal, 20 de enero de 2020). El acercamiento a familiares y víctimas, además de los diferentes eventos que se tienen programados en Guerrero, evidencia una de las características de circulación de este archivo digital; aunque el entorno digital presume una conexión potencial con millones de usarios alrededor del mundo, el objetivo es que los documentos sean conocidos por las comunidades y familiares de víctimas que aparecen en los documentos. "Pero, al ser un archivo digital, tienes las barreras de que México no es un país $100 \%$ conectado a internet y con alfabetización. Sí hay limitantes de que cierta gente no se va a poder meter a ese archivo, por eso la idea de cómo podemos llevar el archivo allá" (María de Vecchi. Comunicación personal, 20 de enero de 2020).

Las reflexiones del equipo de Artículo 19 en torno a la difusión del archivo apuntan a una problematización mucho más compleja de la función de circulación; no solamente se aleja del análisis de la producción y las formas del mensaje, sino que atiende a la relación y mediación de las funciones del medio de memoria con las comunidades del recuerdo a las que se dirije. Es decir, las fronteras entre la función de almacenamiento y circulación del medio de memoria son tan endebles que, sólo a partir de su interacción y mediación, podemos hacerlas intelegibles; ésta es una caraterística que se sustenta fundamentalmente en la constitución comunicacional del medio de memoria.

Por último, para hablar de la función de evocación, se retoma una de las frases de María de Vecchi: "llevar el archivo allá". Los procesos del recuerdo se ponen en marcha a través de señales, esto es, de índices de evocación. Estas señales pueden ser de naturaleza psicológica, aunque, con frecuencia, imágenes, textos o discursos también funcionan como motivaciones del recuerdo (Erll, 2011). Es decir, las funciones del medio de memoria son también un ejercicio recursivo que va de lo colectivo - objetivado en el almacenamiento y circulación- a lo individual -inscrito en el proceso de 
evocación-. "Llevar el archivo allá", como menciona de Vecchi, no es una tarea circunscrita a la circulación; es una definición evocativa de lo que el archivo representa, como concepto, para Archivos de la Represión. El archivo es señal y proceso de evocación en el momento en el que se utiliza como motivación del recuerdo; en este caso, como representación del pasado.

Tras enunciar las características principales de las funciones de los medios de memoria, en tanto procesos colectivos de construcción de memoria, en la siguiente sección se revisan los marcos mediales del recuerdo, donde las funciones mencionadas son claves para comprender los fenómenos mediales que acompañan el surgimiento de Archivos de la Represión.

\section{Marcos mediales}

La tercera categoría que integra la dimensión social del medio de memoria está relacionada con la producción de objetivaciones culturales en un marco mediático. Erll (2011) conceptualiza los marcos mediales de la memoria, es decir, el escenario de producciones mediáticas sobre la memoria y el pasado, con base en los postulados de Maurice Halbwachs (2004), los cuales atribuyen a los marcos sociales la determinación de la memoria individual, en una perspectiva que integra a la memoria y el pasado como fenómenos de la cultura. Según Erll (2011), "los marcos mediales hacen posible y determinan el recuerdo, así como la interpretación que se hace de la experiencia propia y ajena. Las representaciones mediales preforman nuestra percepción y determinan cómo evocamos nuestros recuerdos" (p. 194).

Para operar la categoría de los marcos mediales en el caso de Archivos de la Represión, se revisarán a continuación los productos mediales realizados bajo la nominación de archivo, biblioteca o repositorio digital que, de manera directa o indirecta, se acercan a la temática de la represión en México durante las décadas de 1960 a 1980. La selección corresponde a la relación que los mismos medios o instituciones han establecido con el proyecto. El objetivo final es dar a conocer las principales características comunicacionales del escenario medial sobre el periodo de contrainsurgencia en México.

Uno de los proyectos que, de forma paralela, acompaña el desarrollo de Archivos de la Represión es el archivo digital Mexican Intelligence Digital Archives (MIDAS), también conocido como Archivos del Autoritarismo 
Mexicano. ${ }^{6}$ Cuenta con la colaboración de la Northwestern University, el Center for Research Libraries (CRL), el Colmex y Artículo 19. "The collection is drawn from Mexico's two principal security services, the Dirección Federal de Seguridad (DFS) and the Dirección General de Investigaciones Políticas y Sociales (DGIPS) and covers the period c. 1940 to c. 1985 [La colección proviene de los dos principales servicios de seguridad de México, la Dirección Federal de Seguridad (DFS) y la Dirección General de Investigaciones Políticas y Sociales (DGIPS). Sus materiales cubren el periodo entre 1940 a 1985]" (Center for Research Libraries). El lanzamiento de este proyecto se realizó en el contexto de la conmemoración de los cincuenta años del movimiento estudiantil en México.

Gran parte de los documentos que almacena provienen de la donación de diferentes investigadores que tuvieron acceso a los acervos del AGN. El material se divide en tres colecciones: Archivos de la Dirección Federal de Seguridad, Archivo Sergio Aguayo y Documentos Mexicanos del National Security Archive. Además de compartir la temática histórica de Archivos de la Represión, Archivos del Autoritarismo Mexicano se erige como una respuesta a las políticas de ocultamiento documental por parte del Estado mexicano: "MIDAS is a response to that censorship. It is an international partnership, directed by academics from Mexico, the United States, Great Britain and Europe, and aided by individual researchers who contributed copies, photographs and scans of the documents made during the time the physical archives were available [MIDAS es una respuesta a esa censura. Es una asociación internacional, dirigida por académicos de México, Estados Unidos, Gran Bretaña y Europa, y apoyada por investigadores individuales que contribuyeron con copias, fotografías y escaneos de los documentos realizados durante el tiempo en que los archivos físicos estuvieron disponibles]" (Center for Research Libraries).

La participación de los académicos no sólo debe ser valorada en relación a los aportes y donaciones que realizaron del material digitalizado; Archivos del Autoritarismo Mexicano concibe, desde mi perspectiva, a la academia como el grupo fundamental al que se dirige el archivo digital. Para Jessica Alcázar, "MIDAS responde a una lógica de público de investigación, a diferencia del derecho a la verdad que enmarca Archivos de la

6 https://www.crl.edu/midas 
Represión" (Comunicación personal, 20 de enero de 2020). Los lazos institucionales entre MIDAS y Archivos de la Represión se reflejan en los trabajos colaborativos de digitalización y catalogación documental.

MIDAS ofrece un soporte y resguardo del material documental que ha sido revisado durante varias décadas por investigadoras e investigadores del fenómeno de la represión y el autoritarismo. La organización de los archivos y las herramientas de acceso están mayormente diseñadas para el público académico. En términos generales, bajo las funciones propuestas por Erll (2011) para los medios de memoria, podemos clasificar a MIDAS como un medio de almacenamiento, sin que esto signifique reducir sus capacidades de circulación y evocación. Como parte del marco medial de archivos digitales sobre el periodo de la contrainsurgencia, MIDAS se posiciona como un fenómeno medial con una narrativa que expande geográficamente las posibilidades del recuerdo hacia otras comunidades especializadas, en este caso, del norte de Estados Unidos.

Otro de los archivos que integran el escenario de las objetivaciones culturales sobre la contrainsurgencia en el entorno digital es "México 1968", que forma parte del Archivo Histórico de la Universidad Nacional Autónoma de México (AHUNAM). ${ }^{7}$ Aunque este acervo no está dedicado especialmente al contexto de la represión, en 2018 -en el marco de las conmemoraciones de 1968-, la institución decidió dar a conocer una exposición con los documentos digitalizados relacionados con el movimiento estudiantil.

Hemos diseñado un portal digital abierto donde ofrecemos la imagen digital de cada documento y la ficha descriptiva correspondiente. Son cerca de seis mil documentos: fotografías, gráfica, hemerografía y textos, agrupados en siete colecciones: Ethel Villanueva, Esther Montero, Justina Lory Méndez, Hemerografía sobre el movimiento estudiantil de 1968, Manuel Gutiérrez Paredes, Fernando Serrano Migallón y Movimiento estudiantil. (Universidad Nacional Autónoma de México)

A diferencia de Archivos de la Represión, el portal del AHUNAM se centra únicamente en el contexto de los movimientos sociales estudian-

7 http://www.ahunam.unam.mx/68/index.html 
tiles de 1968 en México. Sin embargo, debido a la trascendencia del movimiento estudiantil como referente histórico en varias de las comunidades del recuerdo que confluyen en Archivos de la Represión, es indispensable integrarlo al marco medial de la contrainsurgencia. Otra de las diferencias principales entre el AHUNAM y nuestro caso de estudio es el nivel de especialización que posee la institución en el campo de la archivística y la circunscripción de este portal dedicado al movimiento del 68 a un acervo general que resguarda la producción documental de la Universidad. El esfuerzo de este portal debe valorarse como una exposición de documentos digitalizados; acción que no ocurre con la mayor parte de su acervo documental, el cual sólo puede consultarse en las instalaciones del Archivo.

Al igual que Archivos de la Represión y Archivos del Autoritarismo Mexicano, el portal del AHUNAM tiene como contexto de creación la conmemoración del 50 aniversario del movimiento estudiantil de 1968. Este dato no debe ser pasado por alto porque este referente histórico constituye uno de los elementos preponderantes de un marco social del recuerdo sobre la represión; por ello, entenderemos estos archivos digitales como productos mediales de una memoria colectiva sobre la contrainsurgencia.

Para terminar la revisión del portal del AHUNAM sobre el movimiento de 1968, de acuerdo a la dimensión social en la que se inscribe, podemos calificarlo como un medio de memoria determinado por la función de circulación, sin obviar las condiciones de almacenamiento y evocación. La narrativa inscrita en este fenómeno medial debe ser observada bajo la significación que tuvo el movimiento estudiantil dentro de la historia de la Universidad: aunque se trata de una narrativa generada en un contexto institucional específico, puede ser interpretada en un escenario nacional.

A diferencia de los dos casos anteriores, M68 Ciudadanías en Movimiento $^{8}$ se aleja de la tipología de archivo digital para definirse como un "repositorio digital sobre los movimientos sociales que, desde 1968 a la fecha, han impulsado el reconocimiento de derechos en México" (Centro Cultural Universitario Tlatelolco). De nueva cuenta, 1968 irrumpe como una fecha paradigmática en la historia y como un referente mnemónico de los movimientos sociales y la represión. Este repositorio no es un fenómeno medial aislado; se integra a una serie de actividades que conmemoran

8 https://m68.mx/

Ortega, G. S. (2021). Dimensión material de un medio de memoria digital. El caso de Archivos de la Represión. Iberoforum. Revista de Ciencias Sociales, Nueva Época, 1(1), 1-37, artículo e000141. https://doi.org/10.48102/if.2021.v1.n1.141 Licencia Pública Internacional - CC BY NC SA 4.0 
los 50 años del movimiento estudiantil en México. "El Centro Cultural Universitario Tlatelolco de la UNAM abrió en 2018 las puertas de la experiencia museística M68, que consta de tres componentes esenciales: una exposición permanente sobre el Memorial del 68 y los movimientos sociales, el repositorio digital M68 Ciudadanías en movimiento y el "Centro de Documentación M68" (Centro Cultural Universitario Tlatelolco). Se trata de un esfuerzo articulado por el Centro Cultural Universitario Tlatelolco (CCUT), en el que el ámbito documental cumple una labor fundamental tanto en la creación del repositorio digital como en el desarrollo del centro de documentación.

Integrado por archivos públicos y privados, por colecciones institucionales y particulares, el repositorio digital se organiza alrededor de diez temáticas principales: El 68 mexicano y los movimientos estudiantiles; Respuestas a la violencia y crímenes de estado; Luchas por la democracia; Feminismo y disidencia de género; Luchas indígenas; Luchas socio-ambientales; Movimientos obreros y sindicales; Movimientos impulsados por la sociedad civil; Movilidad, migración y desplazados, y Arte, cultura y medios digitales en torno a los movimientos sociales. A partir de estas temáticas, podemos observar algunas de las diferencias narrativas entre el repositorio M68 y los otros casos revisados, incluido Archivos de la Represión. Nos referimos a la propuesta de pensar el movimiento estudiantil de 1968 como el inicio de una serie de luchas, acciones y eventos que "han logrado conformar un patrimonio de derechos individuales y colectivos, así como consolidar a la ciudadanía como una fuerza de transformación política y social" (Centro Cultural Universitario Tlatelolco). Es decir, no sólo sitúa dos referentes temporales -1968 y la apertura del repositorio en el presente-, sino que integra una serie de movimientos sociales que acontecieron durante la segunda mitad del siglo XX, planteando así una línea de continuidad narrativa e histórica.

En cuanto a la función que cumple el repositorio digital como medio de memoria, nos enfrentamos a la caracterización de un fenómeno medial con funcionalidad múltiple, similar al caso de Archivos de la Represión. El proceso de digitalización de los diferentes archivos y colecciones es en sí una acción de resguardo y almacenamiento. La organización y exposición del material, acompañado de las acciones conmemorativas del CCUT, se traduce en la función de circulación de recuerdos y saberes colectivos. Finalmente, la centralidad que ocupa 1968 como fenómeno y como concepto 
dentro del repositorio digital, implica un proceso de evocación que, incluso, es reiterado por la institución: "1968 evoca a una época de libertad y júbilo, de memoria y olvido, de sueños y revoluciones, de violencia e impunidad" (Centro Cultural Universitario Tlatelolco).

Otro elemento del repositorio digital M68 es la colaboración de decenas de instituciones en la formación del proyecto, entre ellas, Artículo 19 y el Colmex. Su participación como colaboradores, tanto en el caso de MIDAS como en el de M68, expone una práctica normativa por parte de Artículo 19 en el contexto del aniversario número 50 del movimiento estudiantil. No sólo se trata de la creación de Archivos de la Represión, sino de la articulación y compresión del movimiento estudiantil del 68 como uno de los códigos colectivos y referentes históricos en la narrativa del acceso a la información que estructura Artículo 19. En la Tabla 2, se sintetiza la relación y función preponderante de los diferentes productos mediales que conforma el marco de interpretación comunicacional de Archivos de la Represión.

Tabla 2. Marcos mediales y funciones del medio de memoria

\begin{tabular}{|l|l|l|}
\hline \multicolumn{1}{|c|}{ Fenómeno medial } & $\begin{array}{l}\text { Función como medio } \\
\text { de memoria }\end{array}$ & $\begin{array}{l}\text { Relación con Archivos de } \\
\text { la Represión }\end{array}$ \\
\hline $\begin{array}{l}\text { Archivos del Autoritarismo } \\
\text { Mexicano (MIDAS) }\end{array}$ & Almacenamiento & $\begin{array}{l}\text { Comparte procesos de ca- } \\
\text { talogación con Artículo 19. }\end{array}$ \\
\hline $\begin{array}{l}\text { Portal 1968 del Archivo His- } \\
\text { tórico de la UNAM }\end{array}$ & Circulación & $\begin{array}{l}\text { Identifica el movimiento } \\
\text { estudiantil de 1968 como } \\
\text { referente histórico de la } \\
\text { contrainsurgencia. }\end{array}$ \\
\hline $\begin{array}{l}\text { Repositorio digital M68 } \\
\text { Ciudadanías en movimiento }\end{array}$ & $\begin{array}{l}\text { Almacenamiento } \\
\text { Circulación } \\
\text { Evocación }\end{array}$ & $\begin{array}{l}\text { Participación de Artículo } \\
\text { 19 como institución cola- } \\
\text { boradora. }\end{array}$ \\
\hline
\end{tabular}

Fuente: Elaboración propia

La clasificación de las funciones descritas en la tabla no elimina los postulados que se enunciaron en la sección anterior. Un medio de memoria colectiva lo es en tanto actuación conjunta de los procesos de almacenamiento, circulación y evocación. Para esta tabla, se ha decidido calificar las funciones preponderantes de los fenómenos mediales revisados. Además, se menciona la relación específica que mantienen los productos mediales 
con Archivos de la Represión. Más allá de ahondar en las diferencias y caminos compartidos entre los diferentes medios que integran este marco de análisis, lo importante es comprenderlos como parte del contexto social y cultural que permite, define y actualiza el recuerdo sobre el periodo de contrainsurgencia y represión.

La mayoría de los productos mediales define el año 1968 como su referente histórico, como una fecha y un código que construye el recuerdo de la represión. Este referente será compartido por Archivos de la Represión; la lucha estudiantil es uno de los elementos que articula el recuerdo y olvido del archivo digital, incluso en el contexto de su lanzamiento como parte de las conmemoraciones del 68.

\section{Dimensión material del medio de memoria}

Tras revisar el ámbito social de Archivos de la Represión, definido como medio de memoria, pasaremos a la observación y análisis de su dimensión material. Son dos las categorías bajo las que opera esta dimensión: instrumentos de comunicación y tecnologías mediales (Erll, 2011). Debido a las características específicas de nuestro caso de estudio, se agrega el concepto de archivo digital enunciado por Pablo Colacrai (2009). Con este diálogo, se descifran los niveles materiales que componen el medio de memoria desde una perspectiva comunicacional y centrada en las condiciones propias de un archivo digital. Así, tanto los instrumentos de comunicación como las tecnologías mediales, categorías propias del sistema conceptual de las culturas del recuerdo, serán analizados a partir de los procesos que Colacrai (2009) integra al archivo digital como sistema de información, principalmente las prácticas de comunicación y exteriorización.

Hablar de los instrumentos comunicacionales de los medios de memoria es establecer una relación directa con su función de almacenamiento. En la medida en que se construyen los soportes y registros que permiten el depósito de los recuerdos, accedemos a los sistemas de escritura, la oralidad, la imagen o el video. Incluso se producen soportes, como Archivos de la Represión, donde la convivencia de estos instrumentos de comunicación conduce a un proceso de transición medial, materializado en la digitalización. Para Erll (2011), los medios que se componen de alguno de estos instrumentos poseen una capacidad semiótica y, por lo tanto, una externalización -exteriorización en el caso de Colacrai (2009)- de la memoria colectiva.

Ortega, G. S. (2021). Dimensión material de un medio de memoria digital. El caso de Archivos de la 
En lo que respecta a Archivos de la Represión, los instrumentos comunicacionales que constituyen la capacidad semiótica y narrativa del archivo digital son el sistema de escritura, la imagen (mayormente identificada en fotografías) y el video. Dado que un análisis aislado de estos instrumentos debilitaría la observación de la estructura narrativa del medio de memoria, se observarán y revisarán en conjunto. Para ello, realizaremos una descripción minuciosa del sitio web y de sus diferentes secciones y elementos.

En la página principal de sitio web, se muestran las principales instituciones que colaboraron en la construcción del diseño digital: la Comverdad, Artículo 19 y el Colmex, lo que evidencia el origen social del proyecto. Luego de observar los logos de las instituciones, nos enfrentamos a la imagen central del sitio web; si la analizamos como un instrumento de comunicación compuesto por fotografías, carpetas de expedientes y texto, podemos definirla a partir de su función evocativa. Las fotografías corresponden a los rostros de personas que fueron víctimas de la represión; fueron tomadas en el contexto de detención, la mayoría de las veces arbitraria, realizada por las instituciones de seguridad. ¿Qué narrativa se construye con la inserción de estas fotografías? Las fotografías de detención y de diferentes protestas serán elementos reiterativos en el diseño del sitio web; no podemos concederles un simple acompañamiento o uso decorativo. Como instrumentos de comunicación, poseen una capacidad semiótica, evocativa y comunicacional.

En la Imagen 2, se aprecian tres fotografías de la detención de dos hombres y una mujer. En la parte inferior, se encuentran un par de carpetas con la palabra "Confidencial" en una de sus pestañas. De las carpetas, sobresale el fragmento de un documento. Al lado derecho de estas imágenes, se lee "Archivos de la Represión". En su conjunto, la imagen revela la consulta y el acceso a los documentos que forman parte de los archivos de la represión. Esta narrativa es acentuada y resignificada por las características materiales y contextuales de las fotografías. Como hemos anotado previamente, la represión en México tuvo, entre otras acciones, la práctica de la desaparición forzada de personas. El "encuentro" de estas personas en los archivos conforma una narrativa de hallazgo que se opone a la narrativa de olvido y desconocimiento construida por el Estado. Allí donde el Estado y las instituciones de seguridad negaron su participación en la represión y desaparición de personas, surgen los documentos como evidencia de una contranarrativa. 
Imagen 2. Página principal del sitio web

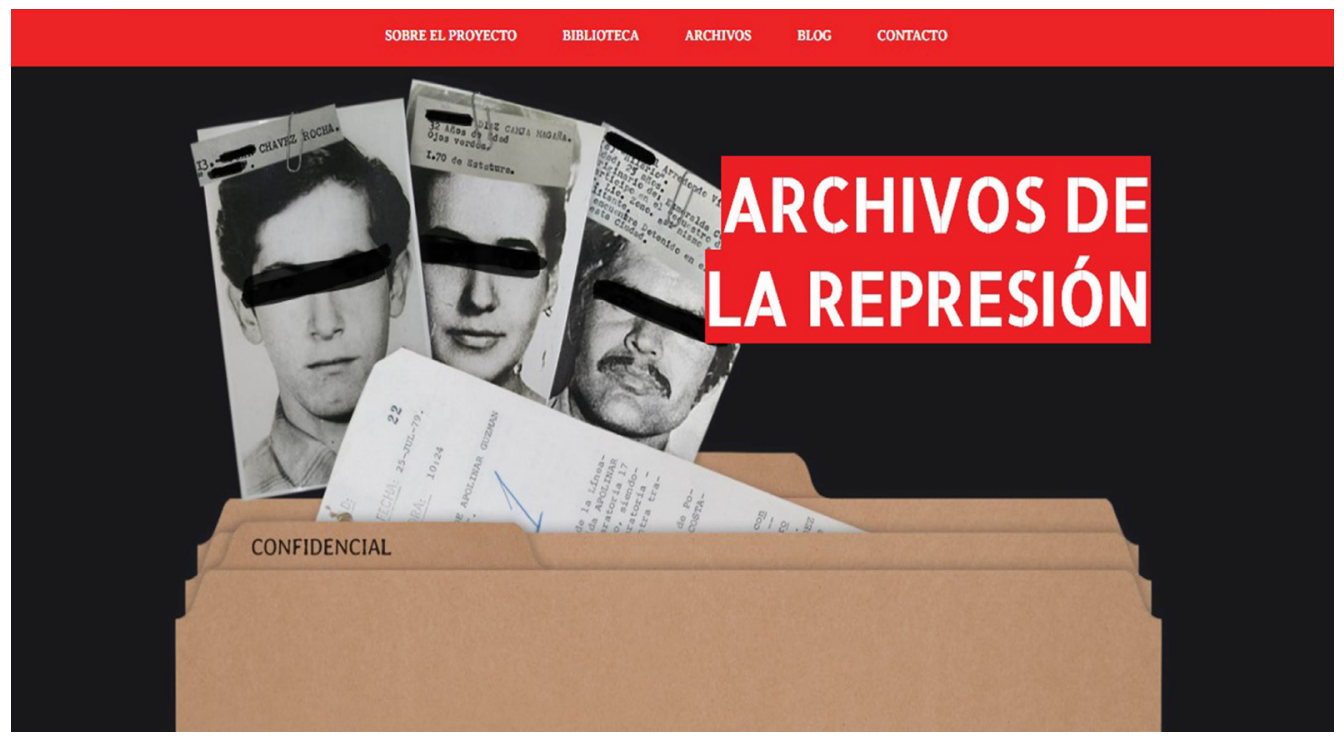

Fuente: Article 19. Archivos de la Represión

Las fotografías también son un índice evocativo del que se han apropiado distintas comunidades del recuerdo, principalmente en Latinoamérica. Los rostros de personas desaparecidas fungen como instrumentos de comunicación más allá del ámbito archivístico y se integran a las movilizaciones y marchas que exigen su aparición con vida. Así, el uso de estas fotografías en Archivos de la Represión se articula como parte de los instrumentos simbólicos sobre la desaparición en un contexto internacional; además, desentrañan el papel de quienes cometieron la desaparición. Puesto que las fotografías forman parte de los archivos de instituciones públicas, el crimen cometido contra estas personas tiene en el Estado a su ejecutor. Esta narrativa señala al gobierno mexicano y sus instituciones de seguridad como perpetradoras de la represión, tortura y desaparición forzada de personas.

Otro de los elementos a resaltar de este tipo de fotografías son las marcas, producto de la acción de testar los documentos. Además de su significado material, éstas dan cuenta de las normativas de acceso y protección de datos personales a los documentos públicos. Tanto la sección del rostro donde se encuentran los ojos como los nombres de las personas serán sujetos de esta marca. Seleccionar imágenes que fueron testadas mantiene una coherencia con los referentes metodológicos que el archivo 
digital plantea para su consulta en su aviso de privacidad: "Usted tiene derecho de acceder, rectificar y cancelar sus datos personales, limitar su uso o divulgación, así como a oponerse al tratamiento de los mismos o revocarlos. Para verificar este procedimiento, visite nuestro aviso de privacidad" (Article 19). El proyecto respeta los datos personales y sensibles de las víctimas de la represión que se documentan en los archivos.

La siguiente sección del sitio web, "Sobre el proyecto", detalla las condiciones en las que surgió y el acervo que lo integra. Además, al ser un sitio en construcción, explora las expectativas que se tienen para el proyecto, entre ellas la de "buscar ser enriquecidos con otros acervos compuestos por documentos y testimonios, esto con el fin de aportar elementos de análisis y problematizar la memoria histórica relacionada con este periodo" (Article 19). Al considerar la integración futura de testimonios, el archivo digital responde a la necesidad de integrar comunidades del recuerdo que, desde su narrativa, supongan una tensión con lo mencionado en los archivos.

La siguiente sección corresponde a "La biblioteca"; ésta "contiene los archivos catalogados. Aquí podrá consultar la información relativa a las personas, servidoras/es públicas/os y organizaciones mencionadas en los archivos" (Article 19). Esta sección es el centro del trabajo de catalogación y descripción documental que realiza el equipo del archivo digital. A diferencia del mencionado Archivo Íntegro de la Comverdad, en la biblioteca se revisa cada uno de los documentos y, con una metodología diseñada previamente, se describe su contenido. A casi dos años de haber publicado el sitio web, se han catalogado 7500 fotografías de las 310000 que integran la totalidad del archivo. Estos números se pueden consultar en la sección dedicada a la numeralia; en ella se explica también que, en los documentos catalogados, se han mencionado a más de 106000 personas, 1853 organizaciones y 1829 servidores públicos.

Otra de las secciones es "Documentos relevantes", cuyo contenido permite comprender el contexto en el que surgió el proyecto. Los documentos son el Informe final de la Comisión de la Verdad del Estado de Guerrero, la Recomendación 26/2001 y las Quejas en materia de desaparición forzada de las décadas de los 70 y 80 -los dos últimos, producidos por la Comisión Nacional de Derechos Humanos (CNDH)-. En términos generales, son documentos referentes a la lucha por el acceso a la información, el esclarecimiento de los hechos ocurridos en la contrainsurgencia y las tareas de identificación de víctimas de desaparición forzada durante ese periodo.

Ortega, G. S. (2021). Dimensión material de un medio de memoria digital. El caso de Archivos de la 
Hemos señalado que los instrumentos de comunicación que dan forma a la dimensión material de Archivos de la Represión son diversos. Atendiendo a esa diversidad, el sitio web cuenta con dos secciones dedicadas a la difusión de videos. El primero de ellos es el video de presentación del proyecto; en él, víctimas, ex comisionados e integrantes del equipo de Archivos de la Represión explican su importancia. Entre las personas que aparecen en el video, se encuentra Ana Cristina Ruelas, exdirectora de la Oficina para México y Centroamérica de Artículo 19, quien expone el valor de los documentos que integran el archivo digital y exige "que específicamente se otorgue la calidad de acceso público irrestricto a todos los archivos de derechos humanos que se encuentran hoy por hoy dentro del Archivo General de la Nación. No pueden permanecer restringidos" (Artículo 19, 2018). Un elemento interesante del video, además de los testimonios, es el uso reiterado de las fotografías de víctimas de la represión (Imagen 3), cuestión que ya ha sido destacada. Los videos de presentación y las redes sociales del proyecto, al ser utilizados en el sitio web, se convierten en el instrumento de comunicación preponderante del proyecto, lo que ratifica la centralidad que poseen las víctimas y sus familiares dentro del diseño y desarrollo del archivo digital.

Imagen 3. Fragmento del video de presentación de Archivos de la Represión

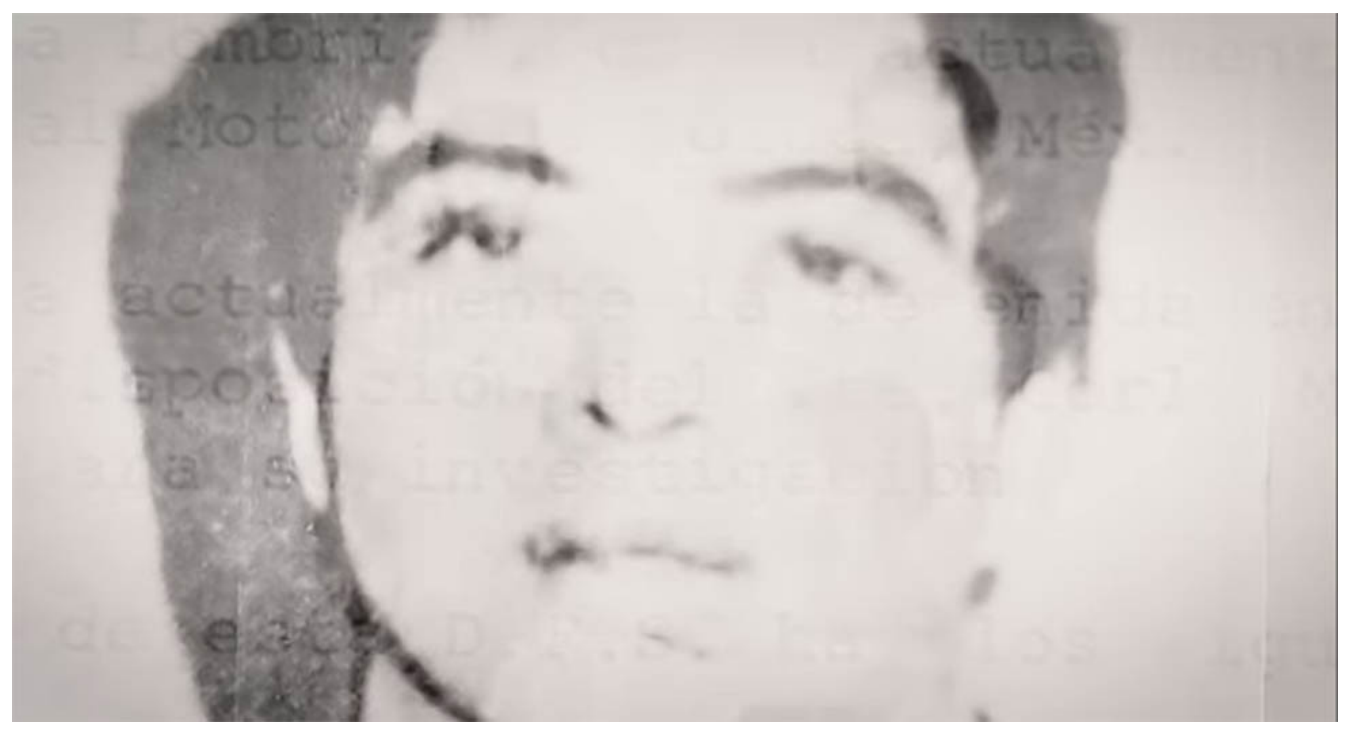

Fuente: Article 19. Archivos de la Represión 
El segundo instrumento de comunicación presentado en formato audiovisual es el enlace a la miniserie documental Desaparecer en México. Conviene rescatar, dentro de la dimensión material del medio de memoria, que los dos productos audiovisuales son instrumentos de comunicación que cumplen la función de circulación del recuerdo. A diferencia del sistema de escritura y las fotografías, los videos atienden a los objetivos de difusión del proyecto. Esta diferenciación resulta novedosa, pues en el trabajo de Erll (2011) los instrumentos de comunicación se concentran en la capacidad semiótica y narrativa que poseen los medios de memoria. En nuestro análisis, además del ámbito narrativo, observamos una condición funcional diferenciada de los instrumentos de comunicación. Mientras que el texto, entendido como sistema de escritura, atiende a la función explicativa y metodológica del archivo digital, las fotografías exploran la función evocativa del pasado y los videos se suman a las tareas de circulación del recuerdo.

Continuando con la descripción de las secciones del sitio web y su capacidad narrativa, Archivos de la Represión brinda un espacio dedicado exclusivamente a las "Últimas noticias" sobre el archivo digital. En esta sección se incluyen diferentes notas periodísticas relacionadas con el lanzamiento del proyecto o con temáticas vinculadas a la represión y el acceso a la información. No se trata de un elemento ingenuo dentro de la arquitectura del sitio, sino de un esfuerzo por circular y difundir el medio de memoria y por colocar a los medios de comunicación como actores fundamentales de los marcos sociales de la memoria colectiva (Halbwachs, 2004).

Como síntesis de la revisión y análisis de los instrumentos de comunicación plasmados en el sitio web Archivos de la Represión, cabe mencionar el carácter central que ostenta la fotografía dentro de la narrativa y las capacidades semióticas del archivo digital. Aunque la mayor parte del acervo está integrado por documentos textuales, el uso de la imagen -especialmente de los retratos de las personas detenidas por las instituciones de seguridad- sustenta la perspectiva comunicacional del sitio web. A través de la fotografía, se anclan una serie de procesos evocativos del pasado, siendo el más importante el hallazgo de las víctimas de desaparición. En sentido opuesto a la narrativa de ocultamiento y restricción de la información, las fotografías significan el potencial informativo del archivo y su constitución como sistema de comunicación del pasado (Colacrai, 2009). Aunque resulte paradójico, para el caso de Archivos de la Represión, el uso de las fotografías consiste en un instrumento de comunicación del olvido.

Ortega, G. S. (2021). Dimensión material de un medio de memoria digital. El caso de Archivos de la Represión. Iberoforum. Revista de Ciencias Sociales, Nueva Época, 1(1), 1-37, artículo e000141. https://doi.org/10.48102/if.2021.v1.n1.141 Licencia Pública Internacional - CC BY NC SA 4.0 


\section{Tecnologías mediales}

Al revisar las características de los instrumentos de comunicación de Archivos de la Represión, exploramos la relación entre éstos y la función de almacenamiento. Algo similar ocurre con las tecnologías mediales y su papel en la consecución de la función de circulación del recuerdo. Existen varios puntos clave que Erll (2011) coloca en esta categoría; uno de ellos es que estas tecnologías "hacen posible la propagación, desde el punto de vista espacial y la transmisión, desde el punto de vista temporal, de contenidos de la memoria colectiva" (p. 182). A partir de esta reflexión, podríamos centrar nuestro análisis en una descripción general de las capacidades mediales del internet; sin embargo, se ha optado por atender las especificidades y herramientas tecnológicas que se despliegan en el archivo digital.

Persiste un proceso imprescindible para dimensionar las tecnologías que asisten en nuestro caso investigado: la digitalización. Archivos de la Represión es una remediación - concepto utilizado por Erll (2011)de una serie de documentos que pertenecen al AGN. Las tecnologías mediales que integran el proceso de digitalización tienen un significado más allá de su carácter técnico; "su materialidad específica, su capacidad y sus límites contribuyen, por su parte, al tipo de mensaje que se transmite" (Erll, 2011, p. 183). Reconocer el aporte de la construcción del mensaje implica exponer los enlaces conceptuales, narrativos y comunicacionales que poseen las tecnologías mediales.

Las tecnologías mediales que serán el centro de nuestro análisis de Archivos de la Represión se ubican dentro de la sección "La biblioteca", mediante la cual accedemos al archivo digital. En su página principal, se explica el contexto internacional de los archivos -de manera especial el latinoamericano- y el papel que han jugado como territorios de disputa y como herramientas que colaboran en los procesos de justicia y verdad. También da cuenta de la historicidad de los documentos que se resguardan y del escenario de restricción al acceso de la información en el que se ven envueltos. No obstante, lo más importante para el proyecto, en el marco de las narrativas que se inscriben en la dimensión material del medio de memoria, es dar a conocer que:

Los documentos que se ponen aquí a disposición pública no contienen toda la verdad histórica, pero forman parte importante de ella. No toda la información que estos documentos contienen narra verídica-

Ortega, G. S. (2021). Dimensión material de un medio de memoria digital. El caso de Archivos de la Represión. Iberoforum. Revista de Ciencias Sociales, Nueva Época, 1(1), 1-37, artículo e000141. https://doi.org/10.48102/if.2021.v1.n1.141 
mente hechos, tomando en cuenta que hay información arrancada por tortura, o elaborada para distorsionar hechos. (Article 19)

Ésta será la narrativa sostenida tanto por la dimensión social del medio de memoria como por las tecnologías mediales que se incorporan a la dimensión material.

En la sección "Notas metodológicas", podemos revisar el uso de tecnologías mediales específicas para el archivo digital. La primera de ellas es Omeka, un software libre de administración bibliotecológica que estructura la organización y exposición de los documentos. El diseño de este software responde a necesidades comunicacionales e históricas, pues "Se trata de un proyecto del Roy Rosenzweig Center for History and New Media de la Universidad John Mason, responsables también del gestor bibliográfico Zotero, que permite la creación de un repositorio mediante la organización de objetos digitales en diferentes colecciones" (Alcaraz, 2012, p. 1). Linda Rath (2016) define Omeka "como una plataforma de bajo costo y amigable con la tecnología que alienta a comunidades académicas y no académicas dinámicas a colaborar, explorar y contribuir con un recurso tecnológico" (p. 158).

Con estas definiciones como referentes, el análisis de Omeka como tecnología medial aborda sus características enteramente comunicacionales, dejando de lado el ámbito informático y de programación. Para Robles Gil, colaborador de Archivos de la Represión,

El internet abre nuevas posibilidades para ejercer los derechos de comunicación de la ciudadanía, sobre todo el derecho a la libertad de expresión e información. Es en este sentido que la tecnología puede ser pensada no desde la tecnocracia, sino desde una estructura de derechos. En este sentido las tecnologías fungen como una cuestión democratizadora de resistencia a la censura, y en este caso, de difusión de la historia. (Artículo 19, 2018)

Omeka es una herramienta flexible que se adapta tanto a las características del material digital como a las condiciones institucionales de los proyectos. Incluso permite la coparticipación desde cualquier lugar de la red y la conformación de repositorios digitales hasta en el ámbito individual y familiar. Al mismo tiempo, contiene herramientas que otorgan marcos básicos de normatividad archivística mediante el protocolo Open 
Archives Initiative Protocol for Metadata Harvesting (OAI-PMH). Este elemento es fundamental para comprender la selección de la plataforma para Archivos de la Represión pues, a pesar de que el proyecto es un esfuerzo de la organización civil, está respaldado por una metodología meticulosa en la descripción y catalogación de los documentos.

Como buena parte de las tareas llevadas a cabo en el archivo digital, la decisión sobre el software fue consensuada con las otras instituciones " $y$ desde El Colegio de México nos dieron, es que no es capacitación, sino la opinión informada, y fue de allí que se tomó la decisión de utilizar Omeka, como las cuestiones más técnicas de cómo funcionaba, como debería funcionar la biblioteca" (María de Vecchi. Comunicación personal, 20 de enero de 2020). Además de revelar la forma en la que se definió la plataforma digital, es necesario explicar la relación entre Omeka y los objetivos culturales y comunicacionales de Archivos de la Represión.

Según Alcaraz (2012), "Omeka se erige como una interesante solución para pequeñas y medianas instituciones que deseen publicar exposiciones virtuales o repositorios que den acceso a sus documentos electrónicos" (p. 12). Omeka no es un software mayormente pensando para funcionar como un archivo que resguarda, como una plataforma de preservación digital, sino como un espacio de exposición, de difusión; como museo o galería, más que como un repositorio. Desde este punto, podemos pensar que, en un proyecto como Archivos de la Represión, el software favorece la función de circulación y, por ende, la condición comunicacional del archivo y la memoria.

Respecto al tema de la adaptabilidad de la plataforma, podemos observar que es empleada en grandes repositorios - como Europeana- ${ }^{9}$ y en proyectos de corte individual; sin importar la magnitud del proyecto, sus usuarios pueden acceder y organizar sus documentos y acervos digitales de acuerdo a sus limitaciones y alcances. Esta adaptabilidad de la tecnología medial representa una capacidad de producción y mediación que va de lo individual a lo colectivo. Bajo el supuesto de que la memoria, en su acepción cultural, está regida, entre otras cosas, por el recuerdo individual y el contexto sociocultural, la elección de un software que se adapte a diferentes

9 https://www.europeana.eu/es

Ortega, G. S. (2021). Dimensión material de un medio de memoria digital. El caso de Archivos de la Represión. Iberoforum. Revista de Ciencias Sociales, Nueva Época, 1(1), 1-37, artículo e000141. https://doi.org/10.48102/if.2021.v1.n1.141 Licencia Pública Internacional - CC BY NC SA 4.0 
aspectos tecnológicos y sociales favorece la implementación de medios de memoria como nuestro caso de estudio.

A estas características generales de Omeka, se suma la posibilidad de trabajar e incluir otro tipo de herramientas que favorezcan la organización y preservación documental, como el estándar internacional de clasificación de archivos Dublincore y algunas herramientas de georreferencia. Dublincore $^{10}$ es un modelo de metadatos que permite estandarizar los recursos informativos en entornos digitales. ¿Cuál es la relevancia mnémica y comunicacional de los metadatos que describen los documentos de un archivo digital? Los metadatos, definidos como la información que se genera a partir de la información, marcan la pauta de la descripción y catalogación de los documentos y de su contenido; en consecuencia, se convierten en los elementos primigenios de las prácticas de búsqueda y organización de la información. En este caso, los metadatos realizados a partir del estándar Dublincore, colaboran en la construcción de las narrativas del pasado que presenta un archivo digital, tanto en el proceso de producción como en el de recepción.

Archivos de la Represión opera con los siguientes metadatos: título, descripción del tema tratado en el documento, organización o institución que crea el documento, fecha en el que el documento original se escribió, naturaleza del documento (oficial/no oficial), localización original en la Galería del AGN, carpeta o caja dentro de la Galería del AGN, nombre del documento digitalizado, información de digitalización del documento original, fecha de digitalización, número de fojas que contiene el documento, nombres de los ciudadanos mencionados en los documentos, nombres de funcionarios públicos mencionados en los documentos, nombre de las organizaciones investigadas mencionadas en los documentos, lugar o lugares que se mencionan en el documento, categoría en la que el documento se inserta.

Varios de estos metadatos son compartidos por la mayoría de los archivos, como es el caso del AGN. Sin embargo, en Archivos de la Represión, la apuesta central en el diseño de metadatos gira en torno a los nombres de los ciudadanos mencionados en los documentos. Esto se puede observar en el diseño del archivo digital: una de las pestañas iniciales corresponde a

10 https://dublincore.org/

Ortega, G. S. (2021). Dimensión material de un medio de memoria digital. El caso de Archivos de la Represión. Iberoforum. Revista de Ciencias Sociales, Nueva Época, 1(1), 1-37, artículo e000141. https://doi.org/10.48102/if.2021.v1.n1.141 Licencia Pública Internacional - CC BY NC SA 4.0 
ese metadato (Imagen 4). Ésta es una acción consciente y dirigida por parte del equipo de trabajo: "Teníamos muy claro la descripción, pero teníamos muy claro la necesidad de poner los nombres, entonces pusimos mucho énfasis en la catalogación de nombres de personas mencionadas en el archivo" (Jessica Alcázar. Comunicación personal, 20 de enero de 2020).

Imagen 4. Metadatos principales del archivo digital

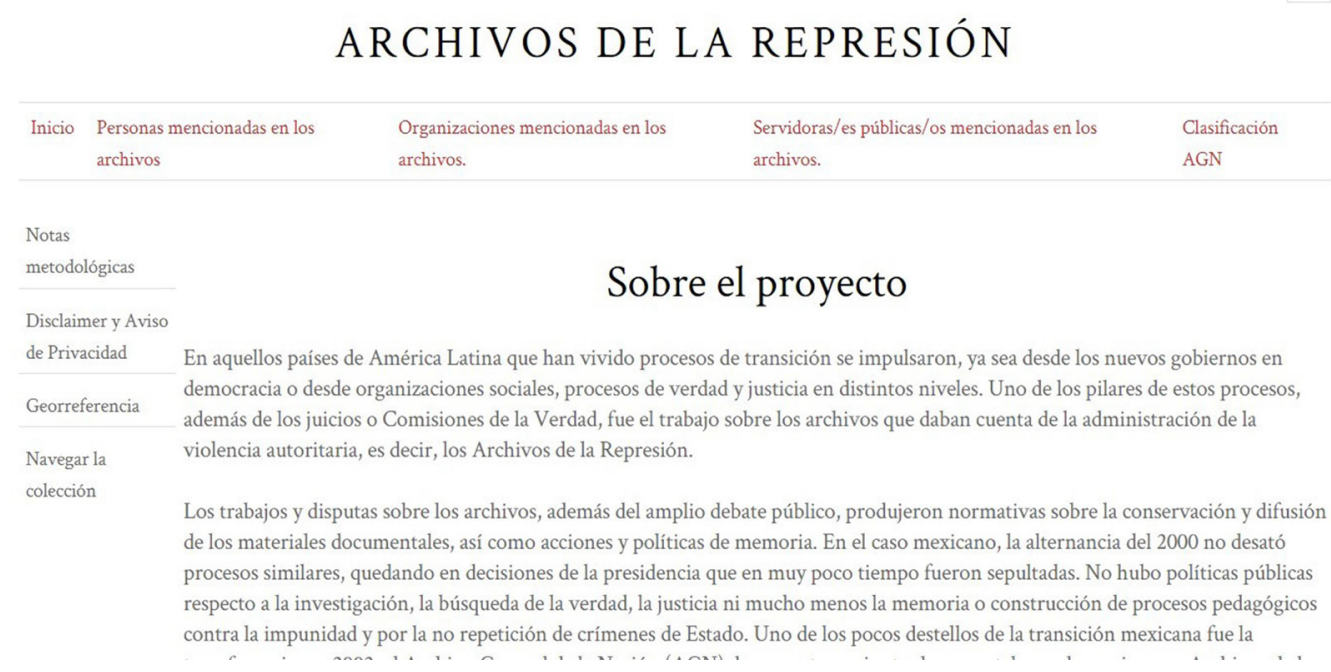

Fuente: Article 19. Archivos de la Represión

Esta capacidad semiótica y narrativa es replicada a través del metadato; la navegación y búsqueda de documentos a partir de los índices que arroja la descripción de personas mencionadas supone la agencia de éstas como articuladoras de la narración del medio de memoria. Erll (2011) sostiene que "las tecnologías mediales no son, sin embargo, depósitos neutrales de semiosis que resultan relevantes para la memoria (procesos semióticos)" (p. 183). Si llevamos esta reflexión a nuestro contexto, podemos sostener que los metadatos diseñados por el personal de Archivos de la Represión a partir del modelo Dublincore - tomado este último como una tecnología medial-, no son "depósitos neutrales". Su selección y aplicación corresponde a los procesos colectivos de construcción de memoria; de manera especial, a la narrativa que explica los procesos de contrainsurgencia a partir de la búsqueda de familiares de personas desaparecidas o detenidas, y del hallazgo de las mismas. 
La navegación por el archivo digital permite interactuar directamente con los nombres de las personas mencionadas en los documentos. El acceso puede ser mediante una búsqueda avanzada o a partir de la revisión de una lista que se organiza alfabéticamente (Imagen 5). Para los familiares de víctimas, resultaría prácticamente imposible acceder a esta información debido a los obstáculos de búsqueda institucionales e instrumentales que plantea una visita al AGN. Valentina López narra su experiencia en la investigación de ambos acervos: "me facilitó mucho poder acceder de manera virtual desde mi espacio a esos archivos, que además yo no entiendo; yo creo debería ser obligatorio que deban ser de fácil acceso, porque es parte de quienes somos como sociedad, como mexicanos, de nuestra historia. Desde cómo se te ofrecen los archivos ya es una narrativa distinta" (Valentina López. Comunicación personal, 21 de abril de 2020). Esta última frase es sustancial para justificar la relación entre los metadatos de un archivo digital y la perspectiva comunicacional con la que estructuran la narración sobre el pasado.

Imagen 5. Organización alfabética de los nombres de las personas que aparecen en los documentos

\section{Personas mencionadas en los archivos}

\begin{tabular}{|l||l|l|l|l|l||l||l|l|l|l|l|l|l|l|l|l|l|l|l|l|l|l||l|l|l|l|l|}
\hline$\# 0-9$ & A & B & C & D & E & F & G & H & I & J & K & L & M & N & O & P & Q & R & S & T & U & V & W & X & Y & Z \\
\hline
\end{tabular}

$\# 0-9$

Antonia Sánchez Riquelme

Carlos Escoto

Carlos Rosales Tejeda

Cutberto Policarpio López (a) "El Campesino", "Hipólito" y "Cutberto"

Encarnación Rosales Archundia

Margarita Acuña Soto

Rafael Arestegui Ruíz

Alicia Hinojosa García

Leovigildo Jiménez Flores

Primo Medrano Mederos

Trinidad Gray

(a) "El Paisa"

(a) "Lalo" (militante del M.A.R)

Fuente: Article 19. Archivos de la Represión

Además de este metadato, se privilegia la organización y búsqueda documental a partir de las organizaciones, servidoras y servidores pú- 
blicos mencionados en los archivos y la clasificación AGN. Dentro de estos metadatos, sobresale el que presenta la información de servidores públicos, lo que materializa las acciones de represión en los nombres y apellidos que las ejecutaron.

El uso de tecnologías mediales como el modelo Dublincore no se traduce en una acción que homologa y replica el formato tecnológico, sino que, desprendiéndose de su neutralidad informática, jerarquiza, guía y determina la forma en la que productores y usuarios del archivo digital se acercan al pasado. Toda tecnología medial conlleva una serie de prácticas; en este caso, la descripción y catalogación documental. Aunque estos procesos son reducidos por la archivística a su simple condición técnica, para Archivos de la Represión, la descripción y catalogación documental son prácticas colectivas de construcción de la memoria, en tanto su papel en la determinación y organización de los documentos históricos y las consecuentes herramientas de búsqueda diseñadas por los metadatos elegidos.

\section{Reflexiones finales}

Cuando se revisa y analiza la dimensión material del medio de memoria, se asiste al escenario donde el fenómeno medial estudiado se conceptualiza -a partir de sus categorías y procesos- en un referente del recuerdo y la memoria colectiva. En este artículo, se observó cómo se llevan a cabo los procesos de institucionalización del medio de memoria a partir de la participación heterogénea de comunidades del recuerdo que construyen diversas significaciones sobre el pasado que soporta el archivo digital. Esta disparidad de posiciones en torno al fenómeno medial faculta su construcción como medio e interpela la participación de diferentes sujetos e instituciones especializadas en los relatos históricos.

La apuesta por conceptualizar al archivo digital como un medio de memoria trasciende los resultados del caso de estudio para instalarse como un término teórico que permite operar y analizar la condición comunicacional del archivo. La relevancia del medio de memoria, objeto principal de la dimensión material, supera las concepciones predefinidas que se le atribuyen al concepto "medio". Comúnmente definido y generalizado a partir de su relación con los medios masivos de comunicación, el medio, como concepto, pierde alcance y complejidad. En este artículo, el medio se volvió un término central y articulador al permitirnos visibilizar los procesos de construcción colectiva e individual de la memoria. No se trata de una

Ortega, G. S. (2021). Dimensión material de un medio de memoria digital. El caso de Archivos de la Represión. Iberoforum. Revista de Ciencias Sociales, Nueva Época, 1(1), 1-37, artículo e000141. https://doi.org/10.48102/if.2021.v1.n1.141 
concepción propia, ya Erll (2011) problematizó el concepto de medio desde una perspectiva interdisciplinar de los estudios de memoria. De forma similar al planteamiento de Raymond Williams (1977), considero el medio, desde su acepción ontológica, como el espacio donde son objetivadas las propiedades de la práctica, es decir, el medio como la materialización de los procesos, mediaciones y prácticas de construcción de la memoria. En la dimensión comunicacional del medio, reside la constitución de la memoria colectiva.

En la capacidad tecnológica del archivo digital, como medio de memoria, se atribuyen y observan sus condiciones materiales. Las tecnologías mediales y los instrumentos de comunicación en entornos digitales configuran la materialidad y definen, estructuran y soportan los actos comunicacionales y las narrativas del pasado inscritas en el archivo digital. En términos sociales, las tecnologías mediales y los instrumentos comunicacionales que integran el proyecto Archivos de la Represión reconfiguran la narrativa sobre la Guerra Sucia, al confrontar la actuación y ejecución de estrategias de represión, como la desaparición forzada, por parte del Estado.

La organización de metadatos y el proceso de descripción y catalogación archivística, comúnmente ceñidos al alcance procedimental y técnico del campo de la archivonomía, funcionan en este caso como tecnologías de mediación del pasado. La digitalización de los documentos de archivos se interpreta más allá de la transformación material, para considerarse como un proceso cultural que acompaña, soporta y actualiza las narraciones de memoria. La centralidad de los nombres de las víctimas en los metadatos del archivo digital y en los instrumentos de comunicación visual y audiovisual conduce hacia una lectura y consulta del archivo donde las voces de las víctimas asumen un rol principal en la narrativa sobre la Guerra Sucia, lo que resulta preponderante en un medio de memoria que apuesta por la comunicación del olvido. Un medio que pondera una narrativa de acceso, memoria, verdad y justicia sobre los crímenes cometidos por el Estado, cuyas pruebas perviven en los archivos de la represión.

\section{Referencias bibliográficas}

Alcaraz, R. (2012). Omeka: exposiciones virtuales y distribución de colecciones digitales. Textos universitaris de biblioteconomia $i$ documen- 
tació, (28). http://bid.ub.edu/28/alcaraz2.htm

Article 19. Archivos de la Represión. https://archivosdelarepresion.org/

Artículo 19. https://articulo19.org/

Artículo 19 (2018, 20 de noviembre). Archivos de la Represión [video]. YouTube. https://www.youtube.com/watch?v=Aeqzd6krT-I\&t

Assman, A. (2012). To remember or to forget: Which way out of a shared history of violence? En A. Assmann y L. Shortt (eds.), Memory and political change. Palgrave Macmillan.

Assman, J. (2011). Cultural memory and early civilization. Writing, remembrance and political imagination. Cambridge Press.

Association for Information Science and Technology (1995). Dublincore. https://dublincore.org/

Center for Research Libraries (2018). Mexican Intelligence Digital Archives. https://www.crl.edu/midas

Centro Cultural Universitario Tlatelolco (2018). M68 Ciudadanías en movimiento. https://m68.mx/

Colacrai, P. (2009). Memoria y archivo, un acercamiento a los dispositivos digitales. Questión, 1(23). http://sedici.unlp.edu.ar/handle/10915/32458

Cook, T. (2013). Evidence, memory, identity, and community: Four shifting archival paradigms. Archival Science, 13(2-3), 95-120. https://doi. org/10.1007/s10502-012-9180-7

Erll, A. (2011). Memory in culture. Palgrave Macmillan.

Europeana Foundation. Europeana. https://www.europeana.eu/es

González Quintana, A. (2005). Los archivos de la seguridad del Estado de los desaparecidos regímenes. Foro por la memoria. https://www.foroporlamemoria.info/excavaciones/archivos_represion.htm

Halbwachs, M. (2004). La memoria colectiva. Prensas Universitarias de Zaragoza.

Ketelaar, E. (2008). Archives as spaces of memory. Journal of the Society of Archivists, 29(1), 9-27. https://doi.org/10.1080/00379810802499678

Kingman, E. (2012). Los usos ambiguos del archivo, la Historia y la memoria. Íconos. Revista de Ciencias Sociales, (42), 17-31. https://doi.org/10.17141/ iconos.42.2012.364

Rath, L. (2016). Omeka.net as a librarian-led digital humanities meeting place. New Library World, 117(3/4), 158-172. https://doi.org/10.1108/ NLW-09-2015-0070

Rufer, M. (2016). El archivo: De la metáfora extractiva a la ruptura poscolo- 
nial. En F. Gorbach y M. Rufer, (In)discplinar la investigación: Archivo, trabajo de campo y escritura (160-186). Siglo XXI.

Silva Catela, L. da (2012). "Lo que merece ser recordado...". Conflictos y tensiones en torno a los proyectos públicos sobre los usos del pasado en los sitios de memoria. Clepsidra. Revista Interdisciplinaria de Estudios sobre Memoria, 1(2), 28-47.

Universidad Nacional Autónoma de México (2018). México 1968. En Archivo Histórico de la Universidad Nacional Autónoma de México. http:// www.ahunam.unam.mx/68/index.html

Vicente, C. (2019). Tiempo suspendido. Una historia de la desaparición forzada en México, 1940-1980. Bonilla Artigas Editores.

Williams, R. (1977). Marxismo y Literatura. Ediciones Península. 